\title{
Feeding Plate of an Eight-day-old Patient Having Veau Type III Cleft Lip and Palate
}

\author{
Komal Ghiya
}

\section{ABSTRACT}

\begin{abstract}
Congenital Cleft lip and palate is a craniofacial defect which results into difficulty in feeding because of the communication between the oral and nasal cavities. Feeding plate restores the gap between the oral and nasal cavities and helps in feeding and reduces the chances of airway problems, regurgitations. This clinical report describes a design and method of fabricating a feeding plate in an 8-day old neonate with a cleft lip and palate.
\end{abstract}

Keywords: Cleft lip and Palate, Feeding Plate, Veau Class III.
Published Online: September 06, 2021

ISSN: $2684-4443$

DOI: $10.24018 /$ ejdent.2021.2.5.88

Dr Komal Ghiya*

Private Practice, Gandhinagar, India. (e-mail: komalghiya049@gmail.com)

*Corresponding Author

\section{INTRODUCTION}

Cleft palate, a congenital anomaly, is a gap within the roof of the mouth caused by failure of the palatal shelves to move back along from either facet of the mouth and fuse through in during the development as an embryo [1]. Cleft lip occurs alone or in association with cleft palate. Clefts have a complex etiology where both genetics and environment play a major role [2].

As a result of the cleft, the oro-nasal communication has diminished ability to create negative pressure which is necessary for suckling. Other complications observed in such children are nasal regurgitation of food, excessive air intake that requires frequent burping and choking subsequently leading to failure to thrive [3].

\section{CASE REPORT}

An 8- day old child was referred by a pediatrician to the dental clinic with the chief complaint of problem in feeding. The parents complained of nasal regurgitation on feeding milk. The weight of the child was $2.7 \mathrm{~kg}$. Clefting of the lip with questionable clefting of the palate was noted in the sonography report in the $8^{\text {th }}$ month of gestation by the radiologist. (Fig. 1) This was the second child of the parents and no history of any clefts was noted in the first child. Moreover, no history of non-inheritable craniofacial defects was noted.

On examination, it was noted that the child has unilateral cleft lip and palate (Fig. 2, 3). According to Veau Classification of cleft lip and palate, it was diagnosed as Veau Type III cleft lip and palate and the after discussion with the parents, fabrication of feeding plate was planned.

A preliminary impression using vinyl polysiloxane impression material was made. During the impression procedure, the baby is made to cry, so that it opens the mouth wide. For the impression, the infant was positioned with the

face downward to forestall airway obstruction and aspiration of the impression material and choking.

Impression of upper gum pad and cleft area were created with the help of hand adaptation to the roof of the mouth by applying minimal pressure.
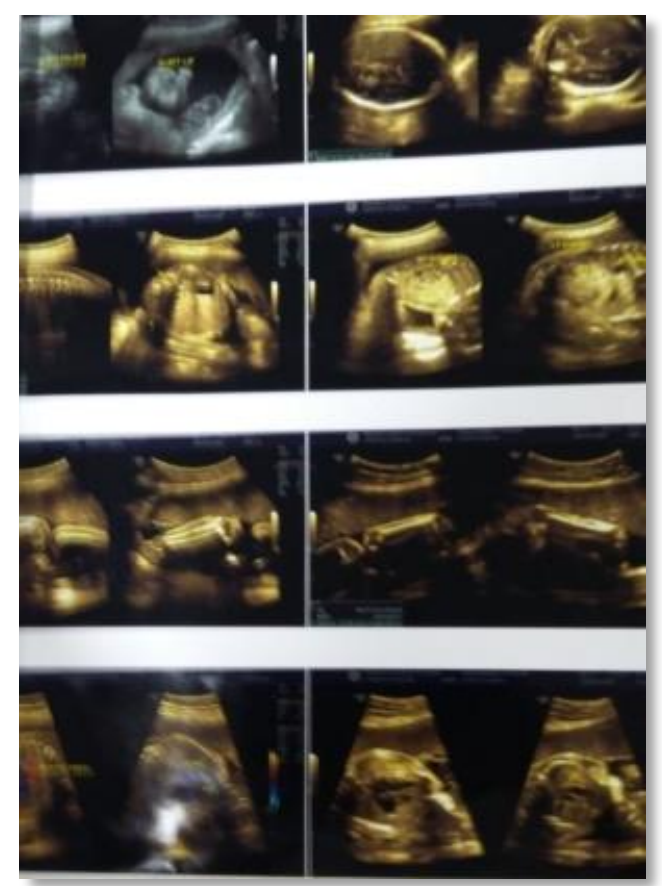

Fig. 1. Ultrasound.

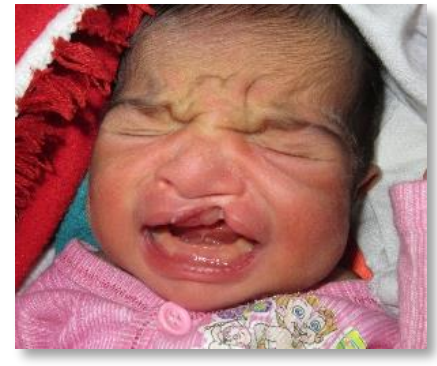

Fig. 2. Extraoral view.

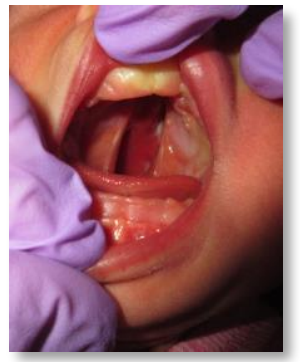

Fig. 3 Intraoral view. 
A primary cast was poured using gypsum type III dental stone and a wax spacer was made to block out the undercuts. Subsequently, a custom tray was fabricated using self-cure acrylic resin. Three holes were made in the posterior palatal surface for better flowability of the material (Fig. 4). Tray adhesive was painted to avoid any fragmentation of the impression material and thereby reducing the risk of accidental aspiration of impression material (Fig. 5).

Using the custom tray, the secondary impression was made, and the final cast was procured thereafter. The undercuts were again blocked using a wax spacer and a 20gauge wire was bent in the shape shown in the figure and embedded in the acrylic plate (Fig. 6). The feeding plate was finished and polished thoroughly to avoid any impingement on the tissues (Fig. 7).

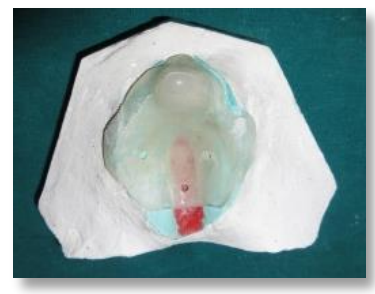

Fig. 4. Primary cast with Spacer and custom tray.

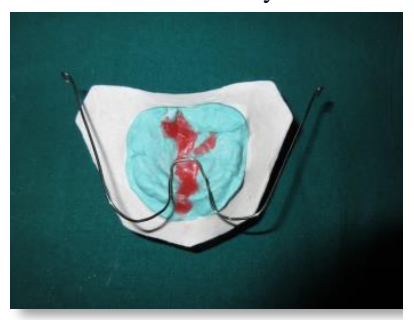

Fig. 7. Feeding plate.

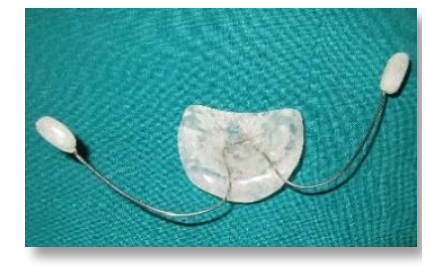

Fig. 6. Wire design on the final cast.

The plate was delivered to the patient by carefully fitting the feeding plate in the infant's mouth and care was taken to avoid the impingement of any muscle attachments by the extraoral extensions (Fig. 8 A, B). Instructions were given to the parents regarding the placement and removal of the appliance and its regular maintenance. Parents were also instructed to use the plate as much as possible. The mother was taught and made to practice the usage of feeding plate and the infant was fed milk before they were relieved from the dental clinic (Fig. 9).

A follow-up visit was planned a week later of the delivery appointment. Mother was enquired regarding the use of a feeding plate. A steady weight gain was also seen. Examination for any possible soreness or ulcerations was also done.
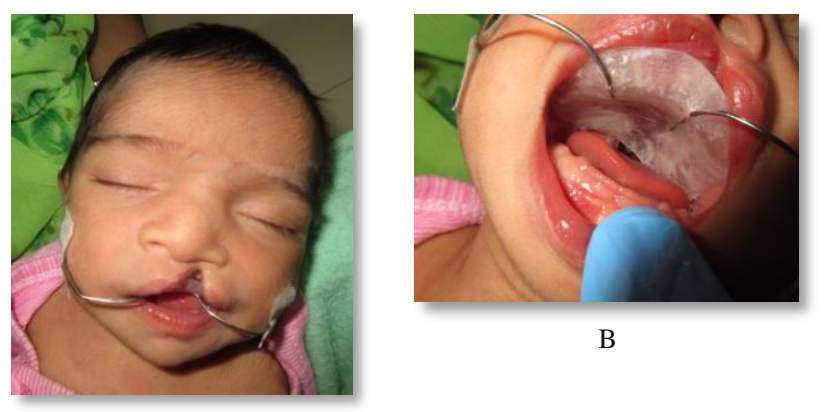

B

A

Fig. 8 A, B. Post delivery intraoral and extraoral view.

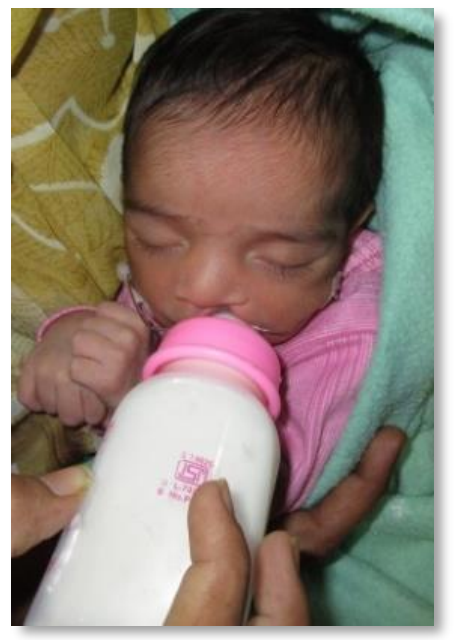

Fig. 9. Post-delivery feeding with the feeding plate.

\section{DISCUSSION}

According to GPT, a feeding prosthesis is an ancillary prosthesis constructed for newborns with cleft palates to allow normal sucking and feeding. It facilitates feeding, lowers nasal regurgitation, reduces the chances of choking and the time requirement for feeding of the child. Furthermore, an obturator prevents the tongue from interfering with the growth of the palatal shelves towards the midline. It also helps to rectify the tongue position and thus helps it to perform its functional role in the development of jaws and promoting speech development. The obturator disallows food to enter the nasopharynx, consequently reducing otitis media and nasopharyngeal infections [4].

Elastomeric impression materials are considered superior for making impressions in patients of cleft due to its elasticity, higher tear strength, accurate reproduction and good dimensional stability which allows multiple cast production using the same impression. The best results are obtained with putty wash additional silicon impression [5].

The use of a custom impression tray allows a uniform thickness of impression material hence, imparting dimensional accuracy of the impression and the prosthesis. ${ }^{6}$ An impression must be securely attached to the tray for an accurate reproduction of the oral cavity. If the material pulls away from the tray during removal from the mouth, the final impression may result into a distorted die. Hence, a tray adhesive has been used in this case [7]. Moreover, in this case, it also reduces the risk of accidental fragmentation of impression material from the tray and aspiration of the material.

The wire design [8] has been modified from an omega loop used previously to squarer central loop to reduce the bulkiness of the tray and hence to make it more compatible for the patient to feed. Moreover, a squarer loop ensures a larger surface area in the acrylic increasing the retentivity of the wire. The wire used here is 20 gauge instead of 19 gauge used previously as a thinner 20-gauge wire will cause less pressure on the facial tissues, along with providing the same functionality as the previous 19-gauge wire would. Vacuumformed materials used in several cases [8] are not economical and oral hygiene is also a concern because a plastic appliance can cause irritation to the palate [9]. 
A comprehensive management of cleft lip and palate can be done by a multidisciplinary team approach. Pediatric dentists play an important role. A prompt intervention by fabrication of feeding plate solves the problem by diagnosing, providing feeding plates, doing nasoalveolar moulding for such patients.

\section{REFERENCES}

[1] Savion I., Michael L., Huband A feeding obturator for a preterm baby with Pierre Robin sequence. J Prosthet Dent, 2005, 93: 197-200.

[2] Rathee M., Hooda A., Tamarkar A., Yadav S., Role of Feeding Plate in \&Oei Palate: Case Report and Review of Literature, IJORL, 2009, 12: 1.

[3] Saunders I.D., Geary L., Fleming P., Gregg T.A. A simplified feeding appliance for the infant with cleft lip and palate. Quintessence Int, 1989; 20:907-10

[4] Erkan M., Karacay S., Atay A., Gunaya Y., Modified Feeding Plate for a Newborn with Cleft Palate. The Cleft Palate-Craniofacial, Journal, 2013; 50(1): 109-112.

[5] Grayson B\., Brecht L.E., Cutting C.B., Nasoalveolar Molding in Early Management of Cleft Lip and Palate, Clinical maxillofacial prosthetics, 2000.p. 63-84.

[6] Payne J.A., Pereira B.P., Bond strength of two non aqueous elastomeric impression materials bonded to two thermoplastic resin tray materials, J Prosthet Dent., 1995; 74(6): 563-568. doi: 10.1016/S00223913(05)80306-3.

[7] Nicholson J.W., Porter K.H., Teresa D., Strength of tray adhesives for elastomeric impression materials, Oper Dent. 1985; 10:12-16.

[8] Sabzar Abdullah, Gourav Singh, Mehbooba Khazir, Amina, Masood Hasan Khan, Research Paper Feeding Plate Prosthesis for an Infant with Cleft Lip and Palate: A Case Report, Journal of Medical and Dental Science Research, vol. 3, issue 10, 2016.

[9] Deepika Kapoor, Deepanshu Garg, Immediate rehabilitation with feeding appliance of a three day old neonate with cleft lip and palate A case report, Journal of College of Medical Sciences-Nepal, vol. 13, No 2, Apr-June 2017.

[10] Goyal S., Rani S., Pawah S., Sharma P., A novel approach for prosthodontic management of patient with cleft of palate, J Indian Soc Pedod Prev Dent, 2017; 35:279-81.

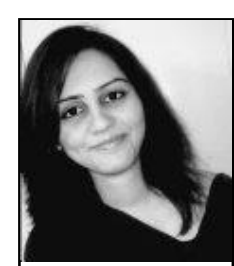

Dr Komal Ghiya was born 4.09.1991 in India.

Degrees: Master of Dental Surgery in pediatric dentistry(2018); Karnavati School of Dentistry, India; Bachelor of Dental Surgery (2014); Government Dental college, Jamnagar.

She is a practicing pediatric dentist since past 3 years at a private practice in Gandhinagar, India. Previously, she has worked as an associate dentist at a private practice in Ahmedabad, India. She has previously published articles in some reputed journals as below:

1. Comparison of plaque removal efficacy of a novel flossing agent with the conventional floss: A clinical study, International journal of clinical pediatric dentistry, 11 (6), 474.

2. Comparative evaluation of demineralization potential of different luting cements for bands used in space maintainers-an in vitro study, European Journal of Molecular \& Clinical Medicine, 7 (11), 7184-7197.

3. Age estimation in children of Ahmedabad population by measurement of open apices of teeth, IOSR Journal of Dental and Medical Sciences, 19 (10), 31-37.

She is currently a member of Gujarat State Dental Council of India. She has also previously been a member of Indian Society of Pediatric and Preventive Dentistry. 